Noordman, J., Dulmen, S.A. van. Shared Medical Appointments marginally enhance interaction between patients: an observational study on children and adolescents with type 1 diabetes

\begin{tabular}{|l|l|}
$\begin{array}{l}\text { Postprint } \\
\text { Version }\end{array}$ & 1.0 \\
\hline Journal website & http://www.sciencedirect.com/science/article/pii/S0738399113002334 \\
\hline Pubmed link & http://www.ncbi.nlm.nih.gov/pubmed/23830238 \\
\hline DOI & 10.1016/j.pec.2013.06.008 \\
\hline
\end{tabular}

This is a NIVEL certified Post Print, more info at http://www.nivel.eu

\title{
Shared Medical Appointments marginally enhance interaction between patients: An observational study on children and adolescents with type 1 diabetes
}

\author{
JANNEKE NOORDMAN $^{\mathrm{A}}$ SANDRA VAN DULMEN ${ }^{\mathrm{A}, \mathrm{B}, \mathrm{C}}$ \\ ${ }^{\text {a }}$ NIVEL, Netherlands Institute for Health Services Research, Utrecht, The Netherlands \\ ${ }^{\mathrm{b}}$ Radboud University Nijmegen Medical Centre, Department of Primary and Community \\ Care, Nijmegen, The Netherlands \\ ${ }^{\mathrm{c}}$ Buskerud University College, Department of Health Science, Drammen, Norway
}

\begin{abstract}
Objective To examine informational and emotional patient-provider and patient-patient communication sequences (i.e. cues and subsequent responses) during Shared Medical Appointments (SMAs) for children and adolescents with type 1 Diabetes Mellitus (T1DM) and their parents .

Methods 57 children/adolescents with T1DM and 36 healthcare providers participated in ten SMAs in seven Dutch hospitals. Parents were present in six SMAs. Video-recordings were made. Communication sequences, including informational and emotional cues and responses were rated using an adaptation of the Medical Interview Aural Rating Scale .

Results 143 patient-initiated cues were identified, followed by 140 provider responses and 30 patient responses. Patients gave more informational than emotional cues. Informational cues were mostly medical-related. Subsequent responses provided by providers and patients contained mostly appropriate information. We identified 17 patient and four parent cues with multiple responses .

Conclusions Almost all cues were identified by healthcare providers and responded to in an appropriate manner. Cues not followed by a provider's response were picked up by other patients. Providers acted as mediator between a patient cue and another patient's response, thereby stimulating the interaction during SMAs .
\end{abstract}


Noordman, J., Dulmen, S.A. van. Shared Medical Appointments marginally enhance interaction between patients: an observational study on children and adolescents with type 1 diabetes

Practice implications Professionals could more explicitly invite all participants to interact with each other, and enable them to have their share in the communication process .

\section{INTRODUCTION}

There is a rising incidence of childhood type 1 Diabetes Mellitus (T1DM) worldwide [1,2]. In the Netherlands, 2.2 of 1000 children (between 0 and 14 years) have diabetes of which about $98 \%$ suffers from type 1 diabetes [3]. Children and adolescents with T1DM have to cope with this chronic disease at an early stage in life. This demands e.g. adhering to a complex treatment, incorporating taking insulin and monitoring blood glucose, facing the threat of future complications and complying with regular control visits at the hospital. Especially in puberty, managing diabetes in daily life can be challenging [4]. Appropriate self-management is crucial [5], supervised by a diabetes team and the patients' parents [4,6-8]. To improve patients' self-management skills and the quality of care, Shared Medical Appointments (SMAs) were introduced in the United States in $1996[9,10]$ and later in the Netherlands [11]. Generally, during an SMA, a multidisciplinary team provides medical care to a homogenous group of patients with comprehen-sive time to go deeper into specific topics [11,12]. SMAs seem especially appropriate for chronic illness management [13]. Patients may feel less isolated with their chronic disease [10] by interacting with, learning from and sharing experiences with fellow patients during an SMA $[14,15]$. A previous study demonstrates that during SMAs more diabetes-related topics are covered in comparison to individual consultations for children and adolescent with T1DM [14]. Furthermore, Graue et al. [16] found that group visits have beneficial effects on health-related quality of life in older adolescents with T1DM. The added value of SMAs is supposed to be the enhanced interaction between patients [17]. A recent study shows that young patients with T1DM indeed value the presence of other patients during SMAs [12]. But whether or not this enhances communication between patients as yet is unknown. To gain insight into the perspective of patients and their feelings during consultations it is important for healthcare providers to address patients' emotions and at the same time deliver adequate information $[18,19]$. Previous research, on individual consultations, indeed found that adequate responses by providers facilitate the disclosure of worries and concerns by patients [19]. Besides, recognizing and providing an appropriate response to patients' cues is an essential part of effective treatment and care for patients [20]. However, most of the time patients do not state their emotions and needs directly, but give (non-)verbal hints or 'cues' that indicate a feeling or issue of importance for the patient [18-25] and need further exploration in order to be heard. Previously, patients' cues and healthcare providers responses were evaluated during individual consultations among cancer patients [18,19,23], fibromyalgia patients [20,21], patients with heart disease [24], in a rheumatology setting [25] and different populations, including children [23]. So far, no research has examined the cues expressed by children and adolescents with T1DM, and responses of healthcare providers to patients' cues, during SMAs. Also, the interaction between children/adolescents with T1DM during SMAs has not been studied before. Insight into the communication process by means of cues and responses is especially relevant as SMAs are supposed to enhance the interaction between patients. 
Noordman, J., Dulmen, S.A. van. Shared Medical Appointments marginally enhance interaction between patients: an observational study on children and adolescents with type 1 diabetes Patient Education and Counseling: 2013, 92(3), 418-425

Therefore, the aim of the present study is to examine: (1) the number and type of informational and emotional cues expressed by children and adolescents with T1DM (and their parents) during SMAs, (2) how health care providers respond to these cues, and (3) to what extent children/adolescents respond to each other's cues during SMAs. As diabetes care involves medical, practical as well as lifestyle issues, patients' and parents' informational cues will also be categorized on content in these three areas.

\section{METHODS}

\subsection{Participants}

Seven Dutch hospitals agreed to participate. A total of ten SMAs took place (three hospitals conducted two SMAs). Five SMAs took place in August and September 2008, as part of a previous study by NIVEL [14], and five SMAs were conducted between September 2010 and December 2011 as part of the present study by NIVEL. The present and previous study had identical study designs [14,15]. Eight SMAs were based on the same intervention protocol [11], two others focused specifically on alcohol use and diabetes. For the present study, hospitals that currently offered SMAs ( $\mathrm{n}=23$ ) were approached for participation (response rate $13 \%)$. Nonparticipating hospitals had practical or organizational reasons not to participate, e.g. the hospitals started to introduce SMAs in their hospital or were in a merging procedure with another hospital. The SMAs were conducted by a team of healthcare providers. Each healthcare team consisted of three to six healthcare providers, such as pediatricians, diabetes nurses and dieticians. One of these providers was also the moderator during an SMA [12]. Patients were included if they had: (1) type 1 Diabetes Mellitus (T1DM), (2) the ability to understand and speak Dutch, (3) were between 6 and 18 years, and (4) were scheduled to have an SMA in one of the participating hospitals.

\subsection{Procedure}

All ten SMAs were held in an outpatient setting. Depending on the hospitals' policy, the SMA could either be a replacement of a routine, individual three monthly followup visit, or an additional visit to the pediatric ward. SMAs were divided into sessions for different age groups: 6-12 and 12-18 years of age [12]. Patients and their parents were sent a letter and informed consent form before attending an SMA, to inform them about the study's purpose and requirements. Prior to an SMA, written informed consent was obtained from patients, parents (in case of children $<12$ years of age) and health care providers. SMAs were video-recorded with one or two unmanned cameras. In the previous study, one camera was used and only the healthcare team was visible [14]. In the present study, two cameras were placed of which one focused on the healthcare team and the other on the patients. Both set-ups allowed us to code all provider-patient and patient-patient interactions in a similar way. Before (T0) and after (T1) attending an SMA patients were asked to fill in a questionnaire. At T0 patients were asked to report their characteristics (age, gender, ethnicity), experienced health and number of contacts/visits with healthcare providers during the last three months. At T1 patients reported their satisfaction with the attended SMA. In case of young children ( $<12$ years), the child filled in the questionnaires together with a parent. A researcher was present before and after the SMA to help patients, if necessary, with the questionnaires. The healthcare providers also 
Noordman, J., Dulmen, S.A. van. Shared Medical Appointments marginally enhance interaction between patients: an observational study on children and adolescents with type 1 diabetes Patient Education and Counseling: 2013, 92(3), 418-425

completed one questionnaire, after an SMA, which contained questions about their character-istics. We used identical questionnaires for the patients and healthcare providers as in the previous study $[12,14,15]$. Our research complied with the Helsinki Declaration. All patients, parents and healthcare providers signed an informed consent form before participation. The studies were carried out according to Dutch privacy legislation. The privacy regulation was approved by the Dutch Data Protection Authority. According to Dutch legislation, approval by a medical ethics committee was not required for this observational study.

\subsection{OBSERVATIONS}

The Medical Interview Aural Rating Scale (MIARS) [26,27] was used to code emotional cues of children and adolescents with T1DM, their parents (if present) and responses of health care providers at these cues, during SMAs. A cue is defined as an utterance (words or sentence) of a patient (direct or indirect) that indicates that the issue is of importance to the patient, asks for clarification (by a provider) or indicates a worry or concern of the patient. Turn-taking was used as the element of observation, which could consist of multiple utterances, words or sentences. A turn is everything a patient says before someone else (a provider or another patient) takes over. Responses were coded if they followed a patient's (or parent's) cue (i.e. lag 1 or more). MIARS does not take into account informational cues and responses, therefore these were added to the scheme in the way as done previously [18]. MIARS has been used before to rate emotional and informa-tional cues and responses of nurses in oncology and rheumatology setting (real-life and simulated consultations) and reported moderate to good inter-rater reliability $[18,19,25,27]$. Using this adapted version of the MIARS, we coded cues of patients and parents in their interaction with healthcare providers, responses of healthcare providers as reaction at patients' or parents' cues and responses of patients in their interaction with other patients (or parents). The cue-responses of the different healthcare providers were put together under the heading of 'the healthcare provider'. This also applies to the cues and responses of 'the patient' and the cues of 'the parent'. In other words, the cues and responses reported per SMA were average for all patients, parents or healthcare providers in any one group. The MIARS coding scheme was incorporated into Observer software [28] to rate the SMAs directly from video.

\subsubsection{Emotional cues and responses}

Emotional cues are (non-)verbal utterances that indicate a level of emotion, including direct and indirect statements. The MIARS describes emotional cues at three levels of intensity: hints- (level 1), mention- (level 2) and clear expression (level 3) of worry or concern. This protocol classifies three types of responses to emotional cues: exploration (eliciting, clarification, or educated guess), acknowledgment (empathic statement, reflection, or checking) and moving away or distancing (blocking further disclosure, switching focus, giving premature reassurance or inappropriate advice). Exploration and acknowledgment are rated as adequate behavior and moving away or distancing as inadequate behavior. Factual clarification (as part of exploration) and overt blocking (as part of distancing) are reported as separate responses in this study (see Section 3). See Appendix A for examples of cues and responses. 
Noordman, J., Dulmen, S.A. van. Shared Medical Appointments marginally enhance interaction between patients: an observational study on children and adolescents with type 1 diabetes Patient Education and Counseling: 2013, 92(3), 418-425

\subsubsection{Informational cues and responses}

In line with a previous study, we defined informational cues as 'verbal informationseeking utterances, including direct questions and indirect statements' [18]. An information cue could be medical, practical or lifestyle-related. Informational cueresponses included exploration, giving appropriate information or giving inappropriate or incomplete information, distancing, overt blocking or referring (see Appendix A). A response was rated as appropriate if the provided information was complete and it covered the same issue as raised by the patient as cue [18]. Exploration was also rated as an adequate response. Distancing and overt blocking were coded as inadequate response behaviors, although these can potentially, given certain aims or contexts, also be considered as appropriate. Referring was considered neither appropriate nor inappropriate.

\subsection{RELIABILITY OBSERVATIONS}

During the previous study $[14,15]$ one of two observers coded five of the SMAs, using the adapted MIARS. Reliability was tested using the intra-class correlation coefficient (ICC). Two half consultations were coded by both observers independently, resulting in a mean interrater agreement of 0.95 (range: 0.88-1.00). In the present study, one of two (other) observers rated the five remaining SMAs, using the adapted MIARS. Two half SMAs were coded by both observers independently resulting in an interrater reliability of 0.96 (range: $0.72-1.00$ ). Observers of the present study re-observed the five SMAs of the previous study $[14,15]$ for the interaction between patients, which was not rated before.

\subsection{STATISTICAL ANALYSIS}

Descriptive statistics were used to analyze patients' cues, patients' responses on another patients' cue, and healthcare providers' responses on patients' cues.

Consequently, we pre-sented communication sequences, by means of cross tables. As sequence we consider each utterance chain consisting of a patient cue as initial utterance followed by the next consecutive utterance(s) of a healthcare provider or/and another patient. During SMAs several different healthcare providers and patients are present. Therefore, sequences could consist of a patient (or parent) cue directly followed by multiple responses from healthcare providers and/or patients. Data were analyzed using Stata 11 [29], except for the ICCs which were calculated using SPSS (version 18.0, PASW statistics, USA).

\section{RESULTS}

\subsection{Participants}

57 children/adolescents with T1DM, of which 14 under the age of 12 years, participated. The majority (68\%) of patients attended an SMA for the first time. On average, six children/adolescents participated per SMA (range: 4-8) (Table 1). 36 healthcare providers participated, of which 12 pediatricians, nine diabetes nurses, eight dieticians, two psychologist/remedial educationalist, two social workers and three other professionals (e.g. assistant, prevention worker). On average, four providers were present during an SMA (range: 3-6). The SMAs had different forms; during eight protocolled SMAs [11] the healthcare providers discussed patients' medical progres-sion and related questions one by one, during two SMAs a specific 
Noordman, J., Dulmen, S.A. van. Shared Medical Appointments marginally enhance interaction between patients: an observational study on children and adolescents with type 1 diabetes Patient Education and Counseling: 2013, 92(3), 418-425

topic (alcohol use and diabetes) was discussed. SMAs had a mean duration of 87.9 min (range: $62-117 \mathrm{~min}$.). One or both parents ( $\mathrm{n}=41$, range: $4-11$ parents) from 35 children/adolescents were present in six protocolled SMAs. During four SMAs none of the parents were present.

\subsection{Frequencies of patients' cues, parents' cues and responses by healthcare providers}

A total of 143 patient cues were identified during ten SMAs. Patients gave on average 14 cues per SMA (range: 1-36). The mean number of cues per minute was 0.16 . Patients gave more informational cues than emotional cues (110 versus 33 ) (Table 2). Informational cues were mostly medical-related (45\%), followed by lifestyle (29\%) and practical (26\%) informational cues. Patients' emotional cues were mainly hints of worry or concern (82\%) .

\section{[TABLE 1] [TABLE 2] [TABLE 3]}

91 parent cues were identified during six SMAs (Table 3). Parents gave on average 15 cues per SMA (range: 8-21). The mean number of cues per minute was 0.19. Parents gave also more informational than emotional cues (72 versus 19), and informa-tional cues were mainly medical-related (72\%). Emotional cues presented by parents were only hints of worry or concern (level 1). Patients gave significantly more cues if parents were not present during SMAs; on average 24 cues when none of the parents were present versus eight cues when parents were present $(P=0.01)$. Although, this outcome correlates with patient's age, since parents were mainly present when children were under the age of 12 years. 140 provider responses on patient cues were identified (Table 2) and 90 provider responses on parent cues (Table 3). Four information cues were not followed by a reaction from a healthcare provider. Responses provided by providers on patient and parent cues contained mostly appropriate information (respectively 51\% and 69\%). Acknowledgement and exploration were mostly provided as a response to a patient's emotional cue (both 42.5\%). Acknowledgement was mostly provided as a response to a parents' emotional cue (42\%), followed by factual clarification (26\%).

\subsection{Communication sequences between patients, parents, providers and other patients}

Table 4 provides an overview of the communication sequences between patients, parents, providers and other patients. Providers responded mostly with appropriate information to a patient's or parents information cue, especially when responding to a patient's practical information cue. Inappropriate (information) responses by providers were relative highest to patient's lifestyle information cues and parents' medical information cues (Table 4). A total of 35 patient responses to other patients' (or parents) cues were presented during SMAs (Table 2). Responses provided by patients contained mostly appropriate information (69\%), most often to medical or lifestyle informational cues. Patients also responded by 'acknowledging' a cue of another patient, predomi-nantly as a response to lifestyle information cues. The amount of patient-patient interaction lags was not more frequent during longer SMAs ( $\mathrm{P}=0.61$ ). The four patient (or parent) cues which were not followed by a healthcare provider's response (see above) were picked up by other patients, who responded by giving appropriate information or exploring of the information cues. 
Noordman, J., Dulmen, S.A. van. Shared Medical Appointments marginally enhance interaction between patients: an observational study on children and adolescents with type 1 diabetes Patient Education and Counseling: 2013, 92(3), 418-425

\subsubsection{Multiple responses to a patient's (or parent's) cue}

To the majority of patient (or parent) cues one healthcare provider or one other patient responded. However, 17 utterance chains consisted of multiple responses to one cue of a patient and four utterance chains consisted of multiple responses to a parent cue. For example, a patient gave an information cue, followed by a distancing response of a healthcare provider, and a second response of another patient who acknowledged the initial cue. Multiple patient-responses to other patients' cues were identified, but almost always a healthcare provider first responded to a patient's (or a parent's) cue (see Table 5) .

\section{[TABLE 4] [TABLE 5]}

\section{DISCUSSION AND CONCLUSION}

\subsection{Discussion}

By using sequence analyses we could get a thorough insight into the complex interaction between children/adolescents with T1DM, parents and healthcare providers $[18,19]$, and also the interaction between patients during SMAs. This study showed that patients with T1DM, and their parents, expressed more informational cues than emotional cues during SMAs. The informational cues were mostly medical-related and emotional cues were mainly hints of worry or concern. Previous studies, during individual consultations, also found that most of the time patient do not state their emotions directly, but give mainly hints of worry or concern [18$25,30]$. The mean frequency of expressed cues (per minute) by children or adolescents in SMAs is somewhat lower than the average amount of cues (per minute) expressed in previous studies, among adult patients with cancer or fibromyalgia during individual consultations $[18,20]$. In contrast, Vatne and colleagues found that children (with cancer) expressed on average more cues than adults, during individual consultations [23]. However, individual consultations and SMAs cannot simply be compared, since they emerge trough different interaction dynamics and rights and responsibilities of speakers. On the other hand, our study also demonstrated that patients gave more cues if (their) parents were not present during SMAs. Although, this outcome correlates with patient's age, since parents were mainly present when children were under the age of 12 years. The presence of parents could have influenced the communication process, especially the interaction between patients. It is possible that children and adolescents interacted less with each other and disclosed fewer problems because of the presence of parents. Moreover, the loss of the child's perspective when parents are present is also reflected in earlier studies [31,32]. The amount of providers could also have influenced the interaction between patients. Future research should address this issue. Secondly, we found that health care providers addressed almost all patient and parent cues during SMAs, and generally did this in an appropriate way. Responses by providers on patients' and parents' informational cues contained mostly appropriate infor-mation.

Acknowledgement and exploration were the most common response to an emotional cue of a patient. These outcomes are fairly in line with a previous study among cancer patients during individual consultations with oncology nurses [18], where patients also expressed mainly informational cues, which were followed by an appropriate information response of a provider. However, the most common 
Noordman, J., Dulmen, S.A. van. Shared Medical Appointments marginally enhance interaction between patients: an observational study on children and adolescents with type 1 diabetes Patient Education and Counseling: 2013, 92(3), 418-425

response to emotional cues by oncology nurses was distancing, followed by acknowledgement [18]. Another study, among simulated cancer patients, also found mainly distancing responses [19]. However, Repping-Wuts et al. [25] found that rheumatology nurses use mainly adequate responding behavior to patients' cues, which is more similar to our findings. Furthermore, Zimmermann et al. [30] found in their review study that patients' cues are often missed by doctors, among several populations and countries. In contrast to this study where only four cues were not followed by a provider's response. Moreover, it is possible that providers in our study did not respond to these cues to give room to patients or parents to respond. Another possibility is that the providers needed to preserve patient confidentiality or shield patients for individual embarrassment. However, at the start of every SMA patient confidentiality was discussed. Overall, it seems that healthcare providers show more (appropriate) response behavior during SMAs for children and adolescents with T1DM than found in other studies during individual consultations $[18,19,30]$. Though, we have to be cautious with these comparisons since these studies represent different patient populations, professionals and settings. More-over, the generalizability of cues and responses across settings is likely to be low.

However, a study by Heyn and colleagues [33] indicates that patients should receive care from an interdisciplin-ary team, consisting of physicians and nurses, representing both informational and emotional support. This could explain the higher (appropriate) response behavior by providers during SMAs compared to individual consultations, since these consultations are represented by a multidisciplinary team of providers. Previous research also suggests that during SMAs the conversational contributions of the different participants is more equally distributed, than during traditional individual outpatient visits [14]. Although appropriate responses were given most of the time, sequence analyses revealed that during SMAs appropriate information to a patient's information cue was mainly given when responding to a practical information cue. Inappropriate (information) responses by providers were relative highest to patients' lifestyle information cues and parents' medical information cues. Inappropriate responses to information cues could comprise of: (1) providing too few, incorrect, confusing or not applicable information, (2) 'distancing' from the cue, i.e. referring to third parties instead of answering the cue or responding in an inappropriate way, or (3) 'overt blocking' i.e. the content of the response is not related to the cue or the cue is ignored. Finally, multiple responses to patient cues were presented during SMAs. These contained a patient cue, almost always followed by a provider's response first and then by one or more patient's responses. The multiple response lags suggest that providers acted as a mediator between a patient cue and another patient's response, stimulating the interaction during SMAs.

\subsubsection{Limitations and implications for future research}

Some limitations should be noted. First, we put the responses of the healthcare providers together under the heading of 'the healthcare provider'. Therefore, we could not differentiate between the professions and their share in the communication process during SMAs. Previous research found that physicians and nurses have different response styles; physicians giving more information and nurses being more emotionally responsive. Therefore, the authors stated that patients should receive both information and emotional support from an interdisciplinary care team [33]. During an SMA, patients receive care from a multidisciplinary team, including 
Noordman, J., Dulmen, S.A. van. Shared Medical Appointments marginally enhance interaction between patients: an observational study on children and adolescents with type 1 diabetes Patient Education and Counseling: 2013, 92(3), 418-425

physicians and nurses, but also psychologists, social workers or dieticians, representing patients' informational and emotional support needs. Second, the SMAs had different forms; during eight protocolled SMAs [11] the healthcare providers discussed patients' medical progression and related questions one by one, but during two SMAs a specific topic (alcohol use and diabetes) was discussed. During the SMAs about alcohol and diabetes professionals provided mainly advice and education. However, the input of and interaction between patients was part of all SMAs. Furthermore, in line with a previous study [18] we decided not to code emotional cues on level zero (as part of MIARS), since these indicate neutral expressions. However, this could have resulted in a lower frequency of patient's and parents' emotional cues. Also, we did not code possible responses presented later in the conversation to an earlier cue. In addition, the observed patient cues were not confirmed by patients themselves. However, agreement between observers was high for the identification of patient cues. Besides, the majority of patients attended an SMA for the first time. These first attendees could have a more cautious attitude (i.e. interaction less and disclosing fewer problems) during an SMA, than patients who are more familiar with SMAs. Lastly, the sample of SMAs, patients and providers was rather small and not representative (e.g. SMAs conducted in different time periods, patients who were first attenders). Therefore, we could not differentiate between patients from different age groups (children or adolescents). Further research is necessary among a larger population, different age groups and patients who attended multiple SMAs. Future research should also address the clinical relevance of SMAs, and the impact of SMAs on patients' stress or anxiety level and information recall. An earlier study did find that group visits have beneficial effects on health-related quality of life in older adolescents with T1DM [16].

\subsection{Conclusion}

Almost all patients' and parents' cues were identified by healthcare providers and responded to in an appropriate manner. Responses that were not followed by a provider's response were picked up by patients. Providers acted as a mediator between a patient cue and another patient's response, thereby stimulating the interaction during SMAs.

\subsection{Practice implications}

Providers could stimulate the participation of children and adolescents even more, since this is supposed to be the main added value of SMAs. Therefore, the moderator (or one of the other professionals) could more explicitly invite all participants to interact with each other, and enable them to have their share in the communication process. In this respect, the role of parents and multiple providers has to be taken into account.

\section{Conflict of interest}

The authors have stated that there are none.

\section{Role of the funding source}

The research was funded by the Dutch Diabetes Research Foundation (present study) and the Health Insurers Innovation Foundation (previous study). They had no role in the study design (collecting, analysis, interpretation of data), writing of the paper and the decision to submit this paper. 
Noordman, J., Dulmen, S.A. van. Shared Medical Appointments marginally enhance interaction between patients: an observational study on children and adolescents with type 1 diabetes

Patient Education and Counseling: 2013, 92(3), 418-425

\section{Acknowledgements}

We would like to thank the patients, parents and healthcare providers who participated in this study. We also thank Arlene Mejino, Frank Tol and Else Zantinge for observing the video-recorded SMAs .

\section{REFERENCES}

[1] Patterson CC, Dahlquist GG, Gyu" ru" s E, Green A, Solte' sz G, the EURODIAB Study Group. Incidence trends for childhood type 1 diabetes in Europe during 1989- 2003 and predicted new cases 2005-20: a multicentre prospective registration study. Lancet 2009;373:2027-33.

[2] DIAMOND Project Group. Incidence and trends of childhood Type 1 diabetes worldwide 1990-1999. Diabet Med 2006;23:857-66.

[3] Baan CA, Poos MJJC. Hoe vaak komt diabetes mellitus voor en hoeveel mensen sterven eraan? [Incidence and mortality rates of diabetes mellitus] In: Volks-gezondheid Toekomst Verkenning, Nationaal Kompas Volksgezondheid. Bilthoven: RIVM, <http://www.nationaalkompas.nl> Nationaal Kompas VolksgezondheidlGezondheid en ziektelZiekten en aandoeningenIEndocriene, voedings- en stofwisselingsziekten en immuniteitsstoornissenlDiabetes mel-litus, 9 februari 2012.

[4] Anderson BJ, Brackett J, Ho J, Laffel LM. An office-based intervention to maintain parent-adolescent teamwork in diabetes management. Impact on parent involvement, family conflict, and subsequent glycemic control. Diabe-tes Care 1999;22:713-21.

[5] Silverstein J, Klingensmith G, Copeland K, Plotnick L, Kaufman F, Laffel L, et al. Care of children and adolescents with type 1 diabetes: a statement of the American Diabetes Association. Diabetes 2005;28:186-212.

[6] Ingersoll GM, Orr DP, Herrold AJ, Golden MP. Cognitive maturity and self-management among adolescents with insulin-dependent diabetes mellitus. J Pediatr 1986;108:620-3.

[7] Anderson BJ, Vangsness L, Connell A, Butler D, Goebel-Fabbri A, Laffel LMB. Family conflict, adherence, and glycaemic control in youth with short duration Type 1 diabetes. Diabet Med 2002;19:635-42.

[8] Lewin AB, Heidgerken AD, Geffken GR, Williams LB, Storch EA, Gelfand KM, et al. The relation between family factors and metabolic control: the role of diabetes adherence. $\mathrm{J}$ Pediatr Psychol 2006;31:174-83.

[9] Noffsinger EB. Will drop-in group medical appointments (digma) work in practice? Perm J 1999;3:58-67.

[10] Noffsinger EB. Physicals shared medical appointment: a revolutionary access solution. Group Pract J 2002;51:16-26.

[11] Seesing F, Raats I. Gezamenlijk medisch consult: Een praktische handleiding [Shared Medical Appointment: a practical guideline]. Houten: Bohn Stafleu van Loghum; 2009.

[12] Mejino A, Noordman J, van Dulmen S. Shared Medical Appointments for children and adolescents with type 1 diabetes; perspectives and experiences from patients, parents and healthcare providers. Adolesc Health Med Ther 2012;3:75-83.

[13] Jaber R, Braksmajer A, Trilling J. Group visits for chronic illness care: models, benefits and challenges. Fam Pract Manage 2006;13:37-40.

[14] Rijswijk C, Zantinge E, Seesing F, Raats I, van Dulmen S. Shared and individual medical appointments for children and adolescents with type 1 diabetes; differences in topics discussed? Patient Educ Couns 2010;79:351-5.

[15] Zantinge EM, Seesing FM, Tol FE, Raats CJI, Spreeuwenberg PMM, van Dulmen AM. Gezamenlijk Medisch Consult: samen naar de dokter. Ervaringen van patie"nten en zorgverleners. [Shared Medical Appointment: together to the physician. Experiences from patients and healthcare providers]. Ned Tijdschr Geneeskd 2009;153:A828.

[16] Graue M, Wentzel-Larsen T, Hanestad BR, Søvik O. Evaluation of a programme of group visits and computer-assisted consultations in the treatment of adolescents with Type 1 diabetes. Diabet Med 2005;22:1522-9.

[17] Noffsinger EB. Running group visits in your practice. New York: Springer Science; 2009. 
Noordman, J., Dulmen, S.A. van. Shared Medical Appointments marginally enhance interaction between patients: an observational study on children and adolescents with type 1 diabetes

Patient Education and Counseling: 2013, 92(3), 418-425

[18] Jansen J, Van Weert JCM, De Groot J, Van Dulmen S, Heeren TJ, Bensing JM. Emotional and informational patient cues: the impact of nurses' responses on recall. Patient Educ Couns 2010;79:218-24.

[19] Uitterhoeve R, De Leeuw J, Bensing J, Heaven C, Borm G, De Mulder P, et al. Cueresponding behaviours of oncology nurses in video-simulated interviews. J Adv Nurs 2007;61:71-80.

[20] Eide H, Sibbern T, Johannessen T. Empathic accuracy of nurses' immediate responses to fibromyalgia patients' expressions of negative emotions: an evaluation using interaction analysis. J Adv Nurs 2011;67:1242-53.

[21] Eide H, Sibbern T, Egeland T, Finset A, Johannessen T, Miaskowski C, et al. Fibromyalgia patients' communication of cues and concerns: interaction analysis of pain clinic consultations. Clin J Pain 2011;27:602-10.

[22] Zimmermann C, Del Piccolo L, Bensing J, Bergvik S, De Haes H, Eide H, et al. Coding patient emotional cues and concerns in medical consultations: the Verona coding definitions of emotional sequences (VR-CoDES). Patient Educ Couns 2011;82:141-8.

[23] Vatne TM, Finset A, Ørnes K, Ruland CM. Application of the Verona Coding Definitions of Emotional Sequences (VR-CoDES) on a pediatric data set. Patient Educ Couns 2010;80:399-404.

[24] Vatne TM, Ruland CM, Ørnes K, Finset A. Children's expressions of negative emotions and adults' responses during routine cardiac consultations. J Pediatr Psychol 2011;1-9.

[25] Repping-Wuts H, Repping T, Van Riel P, Van Achterberg T. Fatigue communi-cation at the out-patient clinic of Rheumatology. Patient Educ Couns 2009;76:57-62.

[26] Heaven C, Green C. Medical interview aural rating scale. Psychological Medi-cine Group. Manchester, UK: Christie Hospital; 2001.

[27] Heaven C, Clegg J, Maguire P. Transfer of communication skills training from workshop to workplace: the impact of clinical supervision. Patient Educ Couns 2006;60:313-25.

[28] Noldus LPJJ, Trienes RJH, Hendriksen AHM, Jansen H, Jansen RG. The Observer Video-Pro: new software for the collection, management, and presentation of timestructured data from videotapes and digital media files. Behav Res Meth Instrum Comput 2000;32:197-206.

[29] Stata [computer program]. Version 11. Copyright 2009 by StataCorp LP, 4905 Lakeway Drive, College Station, TX 77845 USA, 2009, www.stata.com.

[30] Zimmermann C, Del Piccolo L, Finset A. Cues and concerns by patients in medical consultations: a literature review. Psychol Bull 2007;133: 438-63.

[31] Dedding C. Delen in macht en onmacht; kindparticipatie in de (alledaagse) diabeteszorg. [Sharing in power and powerlessness; child participation in (daily) diabetes care]. PhD thesis, Amsterdam; 2009.

[32] Tates K, Meeuwesen L. 'Let mum have her say': turntaking in doctor-parent- child communication. Patient Educ Couns 2000;40:151-62.

[33] Heyn L, Ruland CM, Finset A. Effects of an interactive tailored patient assess-ment tool on eliciting and responding to cancer patients' cues and concerns in clinical consultations with physicians and nurses. Patient Educ Couns 2012;86:158-65 . 
Noordman, J., Dulmen, S.A. van. Shared Medical Appointments marginally enhance interaction between patients: an observational study on children and adolescents with type 1 diabetes Patient Education and Counseling: 2013, 92(3), 418-425

\section{TABLES AND FIGURES}

Table 1

Patients' characteristics.

\begin{tabular}{|c|c|}
\hline Characteristics & Patients $(n=57)$ \\
\hline \multicolumn{2}{|l|}{ Gender (\%): } \\
\hline Female & $53 \%$ \\
\hline Male & $47 \%$ \\
\hline Mean age in years (SD; range) & $\begin{array}{l}14 \text { years (SD: } 2.6 \text {; } \\
\text { range: } 8-18)^{\mathrm{b}}\end{array}$ \\
\hline \multicolumn{2}{|l|}{ Ethnicity $(\%)^{2}:$} \\
\hline Dutch & $79 \%$ \\
\hline Western & $7 \%$ \\
\hline Non-Western & $14 \%$ \\
\hline \multicolumn{2}{|l|}{ Attending an SMA (\%): } \\
\hline First time & $68 \%$ \\
\hline Follow-up & $32 \%$ \\
\hline \multicolumn{2}{|l|}{ Use of care last 3 months (mean; range): } \\
\hline Telephone contacts & 1.3 (range: $0-10)^{\mathrm{f}}$ \\
\hline $\begin{array}{l}\text { Individual consultations } \\
\text { (with pediatridian/diabetes nurse) }\end{array}$ & $1.4(\text { range: } 0-9)^{d}$ \\
\hline SMAs & $0.2(\text { range: } 0-1)^{\mathrm{b}}$ \\
\hline $\begin{array}{l}\text { Experienced health (mean; range) } \\
\text { ( } 1 \text { 'excellent'-5 'bad') }\end{array}$ & 2.5 (range: $1-4$ ) \\
\hline $\begin{array}{l}\text { Satisfaction with attended SMA (mean; range) } \\
\text { (1 'not satisfied'-5 'very satisfied) }\end{array}$ & 4.2 (range: $1-5)^{e}$ \\
\hline
\end{tabular}

SMA: Shared Medical Appointment.

a Ethnicity is based on the definition provided by the Central Bur eau of Statistics (www.cbs.nl).

b $n=55,2$ missing.

c $n=49,8$ missing.

${ }^{4} n=52,5$ missing.

e $n=50,7$ missing. 
Noordman, J., Dulmen, S.A. van. Shared Medical Appointments marginally enhance interaction between patients: an observational study on children and adolescents with type 1 diabetes Patient Education and Counseling: 2013, 92(3), 418-425

Table 2

Total number of patient cues and the different types of responses by health care providers and patients (adaptation of the MIARS), during ten Shared Medical Appointments.

\begin{tabular}{|c|c|}
\hline Elements of the (adapted) MIARS & Frequencies $n(\%)$ \\
\hline Patient cues & 143 \\
\hline Emotional cues & $33(23 \%)$ \\
\hline Level 1 (hints) & $27(82 \%)$ \\
\hline Level 2 (mention) & 5 (15\%) \\
\hline Level 3 (clear expression) & $1(3 \%)$ \\
\hline Informational cues & $110(77 \%)$ \\
\hline Medical & 49 (45\%) \\
\hline Practical & $29(26 \%)$ \\
\hline Lifestyle & $32(29 \%)$ \\
\hline Heal th care providers' responses (on patient cues) & 140 \\
\hline Emotional cues & 33 (24\%) \\
\hline Exploration & $14(42.5 \%)$ \\
\hline Acknowledgement & $14(42.5 \%)$ \\
\hline Factual clarification & $1(3 \%)$ \\
\hline Distancing & $3(9 \%)$ \\
\hline Overt blocking & $1(3 \%)$ \\
\hline Informational cues & 107 (76\%) \\
\hline Exploration & $28(26 \%)$ \\
\hline Appropriate information & 55 (51\%) \\
\hline Inappropriate information & $10(9 \%)$ \\
\hline Referring & $5(5 \%)$ \\
\hline Distancing & $5(5 \%)$ \\
\hline Overt blocking & $4(4 \%)$ \\
\hline \multicolumn{2}{|c|}{ Patients' responses (on cues of another patient or parent ${ }^{2}$ ) 35} \\
\hline Emotional cues & $6(17 \%)$ \\
\hline Exploration & - \\
\hline Acknowledgement & $4(67 \%)$ \\
\hline Factual clarification & - \\
\hline Distanding & $2(33 \%)$ \\
\hline Overt blodking & - \\
\hline Informational cues & $29(83 \%)$ \\
\hline Exploration & 5 (17\%) \\
\hline Appropriate information & $20(69 \%)$ \\
\hline Inappropriate information & $2(7 \%)$ \\
\hline Referring & - \\
\hline Distancing & $2(7 \%)$ \\
\hline Overt blocking & - \\
\hline
\end{tabular}


Noordman, J., Dulmen, S.A. van. Shared Medical Appointments marginally enhance interaction between patients: an observational study on children and adolescents with type 1 diabetes

Patient Education and Counseling: 2013, 92(3), 418-425

Table 3

Total number of parent cues and the different types of responses by heal th care providers (adaptation of the MLARS), during six ${ }^{2}$ Shared Medical Appointments.

\begin{tabular}{lc}
\hline Elements of the (adapted) MLARS & Frequencies $\mathrm{n}(\%)$ \\
\hline Parent cues & 91 \\
Emotional cues & $19(21 \%)$ \\
Level 1 (hints) & $19(100 \%)$ \\
Level 2 (mention) & - \\
Level 3 (clear expression) & - \\
Informational cues & $72(79 \%)$ \\
Medical & $52(72 \%)$ \\
Practical & $17(24 \%)$ \\
Lifestyle & $3(4 \%)$ \\
Health care providers responses (on parent cues) & 90 \\
Emotional cues & $19(21 \%)$ \\
Exploration & $3(16 \%)$ \\
Acknowledgement & $8(42 \%)$ \\
Factual clarification & $5(26 \%)$ \\
Distancing & $3(16 \%)$ \\
Overt blocking & - \\
Informational cues & $71(79 \%)$ \\
Exploration & $6(9 \%)$ \\
Appropriate information & $49(69 \%)$ \\
Inappropriate information & $5(7 \%)$ \\
Distancing & $3(4 \%)$ \\
Overt blocking & $5(7 \%)$ \\
\hline Parents & $3(4 \%)$ \\
\hline
\end{tabular}

a Parents $(n=41)$ were present in six (out of ten) Shared Medical Appointments.

Table 4

Emotional and informational communication sequences, during ten Shared Medical Appointments.

\begin{tabular}{|c|c|c|c|c|c|c|}
\hline \multirow[t]{2}{*}{ Patient' emotional cues ( $n$ ) } & \multicolumn{6}{|c|}{ Responses by healthcare providers ( $n$ ) } \\
\hline & Exploration & Acknowledgement & \multicolumn{2}{|l|}{ Factual clarification } & Distancing & Overt blocking \\
\hline Level $1(n=27)$ & $12(44 \%)$ & $11(41 \%)$ & - & & 3 (11\%) & $1(4 \%)$ \\
\hline Level $2(n=5)$ & $2(40 \%)$ & $2(40 \%)$ & $1(20 \%)$ & & - & - \\
\hline Level $3(n-1)$ & - & $1(100 \%)$ & - & & - & - \\
\hline \multicolumn{7}{|l|}{ Parent' emotional cues (n) } \\
\hline Level $1(n=19)$ & $3(16 \%)$ & $8(42 \%)$ & $5(26 \%)$ & & $3(16 \%)$ & - \\
\hline Level $2(n=0)$ & n.a. & & & & & \\
\hline Level $3(n=0)$ & n.a. & & & & & \\
\hline \multirow[t]{2}{*}{ Patient' informational cues ( $\mathrm{n}$ ) } & \multicolumn{6}{|c|}{ Responses by heal thcare providers $(n)^{2}$} \\
\hline & Explor ation & Appropriate information & Inappropriate information & Referring & Distanding & Overt blocking \\
\hline Medical $(n=49)$ & 17 (35\%) & $24(49 \%)$ & $2(4 \%)$ & $1(2 \%)$ & $3(6 \%)$ & $1(2 \%)$ \\
\hline Practical $(n=29)$ & $5(17 \%)$ & $17(59 \%)$ & $2(7 \%)$ & $2(7 \%)$ & $1(3 \%)$ & $2(7 \%)$ \\
\hline Lifestyle $(n=32)$ & $6(19 \%)$ & $14(44 \%)$ & $6(19 \%)$ & $2(6 \%)$ & $1(3 \%)$ & $1(3 \%)$ \\
\hline \multicolumn{7}{|l|}{ Parent' informational cues (n) } \\
\hline Medical $(n=52)$ & $4(8 \%)$ & $33(63 \%)$ & $4(8 \%)$ & $3(6 \%)$ & $5(9 \%)$ & $3(6 \%)$ \\
\hline Practical $(n-17)$ & $2(12 \%)$ & $13(76 \%)$ & $1(6 \%)$ & - & - & - \\
\hline Lifestyle $(n=3)$ & - & $3(100 \%)$ & - & - & - & - \\
\hline
\end{tabular}


Noordman, J., Dulmen, S.A. van. Shared Medical Appointments marginally enhance interaction between patients: an observational study on children and adolescents with type 1 diabetes Patient Education and Counseling: 2013, 92(3), 418-425

Table 5

Multiple responses to a patient's (or parent's) cue.

\begin{tabular}{|c|c|c|c|c|c|c|c|}
\hline $\begin{array}{l}\text { Utterance } \\
\text { chain }\end{array}$ & $\begin{array}{l}\text { Patient's } \\
\left(\text { or parent's }{ }^{2} \text { ) cue }\right.\end{array}$ & Response 1 & Response 2 & Response 3 & Response 4 & Response 5 & Response 6 \\
\hline 1 & $\begin{array}{l}\text { Emotion } \\
\text { cue (level 1) }\end{array}$ & $\begin{array}{l}\text { Provider; } \\
\text { acknowledgement }\end{array}$ & $\begin{array}{l}\text { Patient; appropriate } \\
\text { information }\end{array}$ & & & & \\
\hline 2 & Information cue & $\begin{array}{l}\text { Patient; appropriate } \\
\text { information }\end{array}$ & $\begin{array}{l}\text { Patient; appropriate } \\
\text { information }\end{array}$ & $\begin{array}{l}\text { Patient; } \\
\text { appropriate } \\
\text { information }\end{array}$ & & & \\
\hline 3 & Information cue & Provider; exploring & $\begin{array}{l}\text { Patient; } \\
\text { acknowledgement }\end{array}$ & & & & \\
\hline 4 & Information cue & Provider; exploring & $\begin{array}{l}\text { Patient; appropriate } \\
\text { information }\end{array}$ & & & & \\
\hline 5 & Information cue & Provider; referring & $\begin{array}{l}\text { Patient; appropriate } \\
\text { information }\end{array}$ & & & & \\
\hline 6 & Information cue & $\begin{array}{l}\text { Provider; appropriate } \\
\text { information }\end{array}$ & $\begin{array}{l}\text { Patient; appropriate } \\
\text { information }\end{array}$ & & & & \\
\hline 7 & Information cue & Provider; distancing & $\begin{array}{l}\text { Patient; appropriate } \\
\text { information }\end{array}$ & & & & \\
\hline 8 & Information cue & Provider; exploring & $\begin{array}{l}\text { Patient; appropriate } \\
\text { information }\end{array}$ & & & & \\
\hline 9 & Information cue ${ }^{2}$ & Provider; referring & $\begin{array}{l}\text { Patient; appropriate } \\
\text { information }\end{array}$ & & & & \\
\hline 10 & Information cue & Provider; distanding & $\begin{array}{l}\text { Patient; } \\
\text { acknowledgement }\end{array}$ & & & & \\
\hline 11 & Information cue & Patient; exploring & Patient; exploring & $\begin{array}{l}\text { Patient; } \\
\text { distancing }\end{array}$ & $\begin{array}{l}\text { Patient; } \\
\text { distancing }\end{array}$ & $\begin{array}{l}\text { Patient; } \\
\text { appropriate } \\
\text { information }\end{array}$ & $\begin{array}{l}\text { Patient; } \\
\text { exploring }\end{array}$ \\
\hline 12 & Information cue & $\begin{array}{l}\text { Provider; appropriate } \\
\text { information }\end{array}$ & $\begin{array}{l}\text { Patient; appropriate } \\
\text { information }\end{array}$ & $\begin{array}{l}\text { Patient; } \\
\text { exploring }\end{array}$ & $\begin{array}{l}\text { Patient; } \\
\text { acknowledgement }\end{array}$ & $\begin{array}{l}\text { Patient; } \\
\text { distancing }\end{array}$ & \\
\hline 13 & Information cue & Provider; exploring & $\begin{array}{l}\text { Patient; appropriate } \\
\text { information }\end{array}$ & & & & \\
\hline 14 & Information cue & $\begin{array}{l}\text { Provider; appropriate } \\
\text { information }\end{array}$ & $\begin{array}{l}\text { Patient; appropriate } \\
\text { information }\end{array}$ & $\begin{array}{l}\text { Patient; } \\
\text { appropriate } \\
\text { information }\end{array}$ & & & \\
\hline 15 & Information cue ${ }^{2}$ & $\begin{array}{l}\text { Provider; appropriate } \\
\text { information }\end{array}$ & $\begin{array}{l}\text { Patient; appropriate } \\
\text { information }\end{array}$ & & & & \\
\hline 16 & Information cue & Provider; exploring & Patient: exploring & $\begin{array}{l}\text { Patient; appropriate } \\
\text { information }\end{array}$ & & & \\
\hline 17 & Information cue ${ }^{2}$ & Provider; exploring & $\begin{array}{l}\text { Patient; appropriate } \\
\text { information }\end{array}$ & & & & \\
\hline 18 & Emotion cue (level 1) ${ }^{2}$ & $\begin{array}{l}\text { Provider; } \\
\text { acknowledgement }\end{array}$ & Patient; distancing & & & & \\
\hline 19 & Information cue & Provider; overt blocking & $\begin{array}{l}\text { Patient; appropriate } \\
\text { information }\end{array}$ & & & & \\
\hline 20 & $\begin{array}{l}\text { Emotion } \\
\text { cue (level 1) }\end{array}$ & Provider; exploring & Patient; acknowledgement & & & & \\
\hline 21 & Information cue & Provider; exploring & $\begin{array}{l}\text { Patient; appropriate } \\
\text { information }\end{array}$ & & & & \\
\hline
\end{tabular}

2 Cue of a parent. 